\section{RevistadePolítica Económica y Desarrollo Sostenible}

Centro Internacional de Política Económica para el Desarrollo Sostenible
Revista de Política Económica y Desarrollo Sostenible

EISSN: 2215-4167 • Vol. 6 (2) • Enero-Junio, 2021: 1-5

DOI: https://doi.org/10.15359/peds.6-2.1

URL: http://www.revistas.una.ac.cr/politicaeconomica

Revista electrónica semestral publicada por el Centro Internacional de Política Económica para el Desarrollo Sostenible

Universidad Nacional, Lagunilla, Heredia Apartado 2393-3000

\title{
Los estímulos económicos que se requieren en este momento
}

\author{
The economic stimuli required at this time
}

\author{
Yessica Espinoza González ${ }^{1}$ \\ yessica.espinoza.gonzalez@est.una.ac.cr
}

Fecha de recibido: 14 de setiembre 2021. Fecha de corregido: 17 de noviembre del 2020.

Fecha de publicación: 31 de enero 2021

\begin{abstract}
Resumen
El mundo enfrenta una crisis sanitaria y económica impredecible, los impactos económicos que ha desencadenado esta doble crisis ha llevado a los gobiernos a implementar planes económicos para intentar mitigar el daño que acarrean las drásticas restricciones impuestas para evitar la propagación del coronavirus. En este artículo se señalan brevemente los estímulos económicos que han implementado algunos países, las restricciones que han tenido y si su aplicación ha sido efectiva.
\end{abstract}

Palabras clave: pandemia, estímulos económicos, diseño, programas

\begin{abstract}
The world is facing an unpredictable health and economic crisis, the economic impacts unleashed by this double crisis has made governments to implement economic plans to mitigate the damage caused by the drastic restrictions imposed for prevent the spread of the coronavirus. This article briefly points out the economic stimuli that some countries have implemented, the restrictions they must consider, and if their application has been effective.
\end{abstract}

Keywords: pandemic, economic stimuli, design, programs

\section{Introducción}

Doce meses han pasado desde que se pronosticó el primer caso de coronavirus en el mundo, situación que no se pensó iba a tener un impacto en la economía tan grande como el que actualmente se está viviendo; las medidas de contingencia que han tenido que aplicar los gobiernos para reducir el contagio han desencadenado la mayor crisis económica de la historia, superando a la crisis financiera del 2009.

1 Economista por la Universidad Nacional. Especialista en Regulación. Actualmente trabaja en la Autoridad Reguladora de los Servicios Públicos (ARESEP) en la Intendencia de Transporte. Cursa además la Maestría Académica en Política Económica para Centroamérica y el Caribe, CINPE- UNA. 
Revista de Política Económica y Desarrollo Sostenible • EISSN: 2215-4167

Vol. 6 (2) • Enero-Junio, 2021: 1-5

DOI: https://doi.org/10.15359/peds.6-2.1

Espinoza González

URL: http://www.revistas.una.ac.cr/politicaeconomica

Lo peor de esta pandemia es que no se sabe cuándo va a acabar. Al empezar con el confinamiento se esperaba ansiosamente que transcurrieran los tres meses (plazo que China aplicó en su población) para que todo regresara a la normalidad como salir a trabajar, comprar, pasear o invertir, tal como se hacía antes; pero conforme pasa el tiempo, la situación se ve lejana, y las vacunas se han vuelto una gran incertidumbre. Ya nadie quiere hablar de cuándo terminará, pues son especulaciones.

La vida de las personas ha cambiado en todo sentido. A los que les ha tocado más duro son aquellos que han perdido sus empleos ( $20 \%$ como promedio mundial), sus empresas están cerradas o quebradas; por otra parte, en los que han podido conservar su fuente de ingresos ahora la prudencia es parte de sus vidas, ahorrar y consumir solo lo necesario es lo más sensato.

El mayor problema es que, mientras la pandemia siga cobrando vidas, una gran parte de la población va a vivir con miedo y con precaución; incluso, aunque algunas personas aún conservan sus empresas y trabajos, se desconoce por cuánto tiempo más podrá ser así. La pandemia implica cambios importantes en la dinámica económica, cultural y social de cómo las personas conviven en sociedad.

La economía es una red compleja de partes interconectadas: empleados, empresas, proveedores, consumidores, bancos e intermediarios financieros. Todos son empleados de otra persona (cliente, prestamista, etc.); es decir, si uno de estos vínculos comprador-vendedor se rompe por la enfermedad o políticas de contención, el resultado será una cadena de interrupciones en cascada (Balwin, 2020).

\section{Sobre los estímulos económicos}

En este contexto, la difícil labor de los gobiernos es tratar de mantener los vínculos económicos, es decir, que la relación consumidor-empresa-consumidor siga en pie.

Los gobiernos han decidido actuar a través de estímulos. Un estímulo es una acción cuyo propósito es generar una reacción; en el caso de la economía, suele estar muy vinculado a las políticas monetaria y fiscal y, generalmente, corresponde a medidas que toman los gobiernos para influir en la actividad económica, ya sea para acelerar o frenar alguna variable, por ejemplo el consumo o la inversión.

Las medidas ejecutadas por los gobiernos se traducen en inyecciones de capital, otorgadas a los consumidores u empresas indirectamente a través de bonos, subsidios u otras medidas. Su propósito es que los consumidores gasten o inviertan dinero, y evitar el quiebre económico de las empresas, que pueden mantener a su vez a los empleados. De esta forma, los gobiernos procuran el funcionamiento de la economía; por ejemplo, para amortiguar el golpe a la economía debido a la pandemia del coronavirus Japón aprobó USD 296.000 millones, Estados Unidos aprobó un paquete de USD 3 billones, Noruega utilizó 38.000 millones de euros de su fondo soberano, entre otros. 
Revista de Política Económica y Desarrollo Sostenible • EISSN: 2215-4167

Vol. 6 (2) • Enero-Junio, 2021: 1-5

DOI: https://doi.org/10.15359/peds.6-2.1

Espinoza González

URL: http://www.revistas.una.ac.cr/politicaeconomica

En el contexto actual, es importante considerar dos aspectos básicos: en primer lugar, muchos países antes de esta doble crisis no tenían la mejor situación económica; algunos ya luchaban contra déficits altos, problemas políticos, y estructurales. Otros países apenas estaban superando crisis pasadas; por ejemplo, el virus del ébola o la crisis financiera. A nivel global el crecimiento económico apenas empezaba a repuntar; según las proyecciones para el 2020, se esperaba un crecimiento del 3\% en la economía mundial.

En segundo lugar, este virus ha mostrado características muy particulares: su propagación ha sido muy rápida y su impacto mundial, además, su duración ha sido inesperada e incierta, lo cual ha llevado a los gobiernos a tomar medidas aceleradas y quizás poco planeadas.

En razón de lo anterior, se plantean las siguientes preguntas: ¿Qué estímulos requieren los países en este momento? ¿Los estímulos actuales pueden cumplir con los resultados esperados?

Las experiencias vividas en estos meses están demostrando que no solo el monto de dinero inyectado a la economía es importante, sino también el diseño de los programas. Así lo demuestra el efecto producido por los estímulos del gobierno de Estados Unidos, pues muchos de los millones de dólares predestinados para ayudar a las empresas más pequeñas no fueron entregados a las personas con necesidades reales, y el propósito de estos estímulos -cuya finalidad era conservar a la gente trabajando y consumiendo- no se está logrando. En abril del 2020 la tasa de desempleo en Estados Unidos alcanzó un 14,7\%: la más elevada después de la Segunda Guerra Mundial, y aunque para julio ya fue un poco más baja (10,2\%), es una tasa muy por encima del promedio del desempleo, a pesar del gran paquete de estímulos emitido por el país.

Lo anterior produce una mala canalización de mucho del dinero entregado a través de estímulos económicos, que acaba de manera ociosa y guardado en cuentas bancarias. Esto aunado a la incertidumbre de empresas y consumidores, quienes posponen sus planes de invertir y consumir, produce que los objetivos no se alcancen y sea nulo el efecto multiplicador.

Por el contrario, en aquellos países que han logrado entregar el dinero a las empresas y hogares necesitados, suponiendo que fue así, muchos de ellos actualmente se están enfrentando a un nuevo problema. Al prolongarse tanto esta crisis, algunos gobiernos ya se están quedando sin fondos, y es necesario continuar la entrega de los estímulos económicos; por ejemplo, Costa Rica entregó el bono Proteger durante tres meses a 533 mil familias; sin embargo, como lo manifestó el presidente Carlos Alvarado, no hay de dónde conseguir más recursos para seguir entregando dinero a las familias que lo necesitan, y se está a la espera de la aprobación de nuevos préstamos.

Los estímulos económicos han sido mal diseñados en algunos países, o pueden estar bien diseñados pero existen factores exógenos que disminuyen su efectividad, y es por ello que no se está obteniendo el efecto esperado o son insuficientes para mantener la balanza de pagos equilibrada. La mayoría de los gobiernos no estaban preparados para enfrentar una crisis de tal magnitud.

Quizás estudiando detenidamente cómo han actuado los gobiernos de Dinamarca o Noruega al aplicar los estímulos económicos, se logren identificar los puntos débiles de los 
Revista de Política Económica y Desarrollo Sostenible • EISSN: 2215-4167

Vol. 6 (2) • Enero-Junio, 2021: 1-5

DOI: https://doi.org/10.15359/peds.6-2.1

Espinoza González

URL: http://www.revistas.una.ac.cr/politicaeconomica

demás países en los cuales las medidas han sido ineficaces. Por ejemplo, el gobierno danés se dirigió a las empresas del país afectadas, con el fin de abonarles el $75 \%$ de los salarios de sus empleados y evitar los despidos masivos, con la condición de que mantuvieran a sus empleados en las planillas, conservando así el poder adquisitivo de los trabajadores.

En el caso del país noruego, siempre se ha caracterizado por ser un modelo mundial en seguridad, salud y educación; ha sido uno de los primeros en reaccionar para afrontar esta pandemia. Entre las medidas utilizadas para su recuperación económica se destaca el aumento del gasto, el cual ha sido primordial, además de impulsar una reestructuración verde de cara al futuro.

\section{Conclusiones}

Los estímulos dependen de la condición de cada país y se debe considerar que muchos países enfrentan este virus con grandes restricciones presupuestarias, como es el caso de Costa Rica, Haití, Honduras, entre otros. Pensar en diseñar o redireccionar los estímulos económicos hacia medidas similares a las de los países escandinavos, en donde se apoye a los sectores económicos gravemente afectados, podría ser la clave para mitigar el impacto ocasionado por la pandemia.

En este sentido, los estímulos económicos que se requieren en este momento van dirigidos a prevenir los despidos, aliviar al mercado laboral y ayudar a las empresas sin que tengan que enfrentarse a la quiebra. Proponer planes de compensación salarial temporal para los empleados que se arriesgan a la terminación de su contrato, o planes de compensación para los gastos fijos de las empresas, son algunas de las medidas económicas que han aplicado los países escandinavos, que han sido efectivas y que podrían ser ejemplos por seguir.

Para el caso en particular de Costa Rica, los estímulos económicos fueron dirigidos directamente a las familias afectadas, y no a las empresas (contrariamente a lo que se hizo en Dinamarca); si estas ayudas hubieran sido canalizadas a las empresas, quizás el desempleo no habría alcanzado la escandalosa tasa de un $22 \%$ para noviembre de este año.

En cualquier crisis, y en particular para la actual, si se mantiene el contrato entre empresa y trabajador, es más fácil volver a la normalidad cuando los problemas desaparecen. Es decir, tratar de mantener los vínculos económicos es la clave para superar esta crisis.

\section{Referencias bibliográficas}

AFP (15 de julio, 2020). Éxito de medidas contra el coronavirus en Noruega lleva a funerarias al borde de la quiebra. DW. Disponible en https://www.dw.com/es/\%C3\%A9xito-demedidas-contra-el-coronavirus-en-noruega-lleva-a-funerarias-al-borde-de-la-quiebra/a54182770\#: :text=El\%20Mundo- 
Revista de Política Económica y Desarrollo Sostenible • EISSN: 2215-4167

Vol. 6 (2) • Enero-Junio, 2021: 1-5

DOI: https://doi.org/10.15359/peds.6-2.1

Espinoza González

URL: http://www.revistas.una.ac.cr/politicaeconomica

Balwin \& Weber (2020). Mitigating the Covid Economic Crisis: Act Fast and Do Whatever It Takes. Londres: CEPR Press.

DerBlaueMond (24 de marzo, 2020). La economía del Start/Stop como solución definitiva para salvar la crisis del coronavirus: Dinamarca ya la aplica. El Blog Salmón. Disponible en https://www.elblogsalmon.com/economia/economia-start-stop-como-solucion-definitivapara-salvar-crisis-coronavirus-dinamarca-aplica

Expansión (diciembre, 2020). Estadísticas de desempleo de Estados Unidos. Datosmacro.com Disponible en https://datosmacro.expansion.com/paro/usa?sc=LAB-

Prensa Latina (02 de julio, 2020). Stiglitz afirma que estímulos económicos de Estados Unidos fallaron. El País. Disponible en https:/www.elpais.cr/2020/06/02/joseph-stiglitz-afirmaque-estimulos-economicos-de-ee-uu-fallaron/ 